\title{
Experimental Investigations of Hot Forging Die Surface Layer of Skd61 Steel in Die Sinking Electrical Discharge Machining
}

\author{
Banh Tien Long ${ }^{1}$, Ngo Cuong ${ }^{2}$ and Nguyen Huu Phan ${ }^{2}$ \\ 1. Materials and Industrial Instrument, Machining Engineering College, Hanoi University of Science and Technology, Hanoi, Vietnam \\ 2. Technical-Economics College, Thai Nguyen University, Vietnam
}

Received: July 24, 2014 / Accepted: August 16, 2014 / Published: August 25, 2014.

\begin{abstract}
Electrical discharge machining is an important manufacturing process for tool mould and die industries. The results of the research about EDM show that the performance of die sink reduced due to a change in the material quality of the surface layer than the base material. The article presents the result of the study on the hot forging die surface layer of the SKD61 hot die steel (surface roughness, surface microscopic hardness, microscopic structure of the surface layer, EDS analysis of the surface layer) after die sinking electrical discharge machining using a tool of titanium and copper in oil dielectric.
\end{abstract}

Key words: EDM, surface roughness, microscopic hardness, microscopic structure, EDS analysis, titanium electrode, Cu electrode.

\section{Introduction}

Electrical discharge machining (EDM) is widely used in the production of forging dies. Its use is particularly intense when very complex shapes on hard materials with a high geometrical and dimensional accuracy are required [1]. Moreover, there is no direct contact between the electrode and the work piece; this eliminates the mechanical stresses, chatter, and vibration problems associated with traditional machining [2]. However, the technological capability of the process has limited its low machining efficiency and poor surface finish restricted. The surface layer after using electrical discharge machining with the topography, metallurgical and physicochemical properties is changed considerably [3, 4]. Especially, EDMed surface has a white layer having microscopic cracks with very low toughness [5] which reduce the ability of the working dies. These variations of surface

Corresponding author: Nguyen Huu Phan, professional technique, research field: electrical discharge machining. E-mail: Phanktcn@gmail.com. layer have reduced the working ability of mould, so that we need some methods to increase the surface quantity of it. Prior research has shown that, during machining of the workpiece, material is transferred from the electrode material through the plasma onto the surface of workpiece is also appreciable [6]. Other studies of compacted $\mathrm{Ti}$ powder electrodes have reported improvement in the working lifespan of the die by a factor of three to seven times [7-9].

In this paper, we describe die sinking EDM test results of the surface material layer of hot forging die made fromsteel SKD61 using a tool electrode of titanium and copper. The study aims at evaluating and analyzing the performance of hot forging die surface layer and the amount of material transfer taken place from the tool electrode to the machined surface and reviewing the effectiveness of the use of titanium electrode in die produced. Then the technology-oriented is used to improve the perfomance of forging die in die sinking EDM. 


\section{Experiments}

\subsection{Experimental Setup}

Experiments have been conducted on the Electrical Discharge Machining Cnc-Ea600l of Jsedm-Jiann Mechinery \& Electric Industrial Co.Ltd-Taiwan. The material used for work piece was SKD61 (JIS-Japan) Tool steel having a hardness of $(490 \div 547) \mathrm{HV}$. The tool materials selected for this investigation were titanium and copper, shown in Fig. 1. The dielectric fluid used experimental was oil (ELEC CTROL). The input process parameters used during experimentation is presented in Table 1.

\subsection{Instruments Used for Analysis}

The following output parameters were studied during the course of this experimentation: Chemical composition, microstructure, surface hardness, surface roughness and surface appearance. Surface roughness was measured by a SJ-400 of MITUTOYO, JAPAN). Microstructure of some selected samples was investigated on scanning electron microscope (model JSM 6490) of JEOL, JAPAN. X-ray diffraction analysis was carried out on X-ray diffraction machine, (model Axiovert 40MAT) of CARL ZEISS, GERMAN. Microscopic hardness was measured on micro hardness tester (model Indenta Met 1106) of BUEHLER, USA. Chemical compositions of the machined surface was analyzed Energy Dispersive Spectroscopy (EDS) (model JSM-6490LA) of INSTITUTE OF MATERIALS SCIENCE-Vietnam Academy of Science and Technology.

\section{Results and Discussion}

\subsection{Surface Layers after EDM}

After EDM, the samples are cleaned and cross-section of die sink surface machined. The structured testing of the surface layer by EDM has showed in Figs. 2 and 3 and Tables 2 and 3.

The Cross-sectional structure of the SKD61 steel surface by EDM using a tool electrode of titanium and copper includes 3 layers: The white layer, heat affected zone and base metal.

\subsubsection{The White Surface}

This is the outermost layer, light-colored, with relatively high thickness. Cu electrode: $(10.54 \div 24.06) \mu \mathrm{m}$, Ti electrode: $(15.13 \div 24.06) \mu$ mand most distinctive with the remaining layers. This layer is formed when the electrode and workpiece materials are melted, evaporated, not only swept away by the dielectric fluid but also cooled again at high speed.

The white layer which contains microscopic cracks is distributed quite densely in approximately equal thickness as the white layer. The larger size of the microscopic cracks in the die produced using a Ti

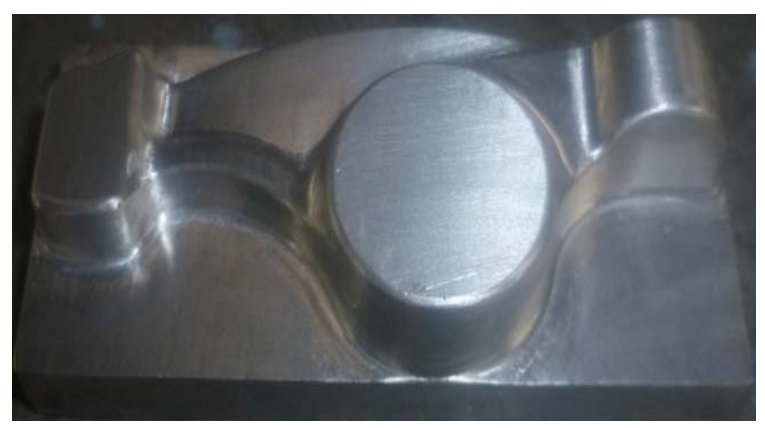

Fig. 1 Electrode used.

Table 1 Machining conditions.

\begin{tabular}{ll}
\hline Parameters & Treatment conditions \\
\hline Intensity of discharge $(\mathrm{A})$ & 4.5 \\
Pulse-on time $(\mu \mathrm{s})$ & 150 \\
Pulse-off time $(\mu \mathrm{s})$ & 2 \\
Dielectric & Kerosene oil (Electrol) \\
Polarity & Positive \\
Machining time & $1 \mathrm{~h} 35$ min $52 \mathrm{~s}$ \\
Voltage of discharge $(\mathrm{V})$ & 45 \\
Tool material & Copper, Titanium \\
\hline
\end{tabular}



Discharge Machining

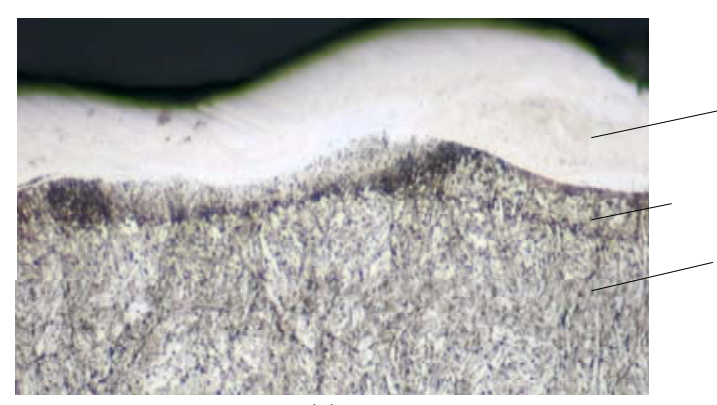

(a)

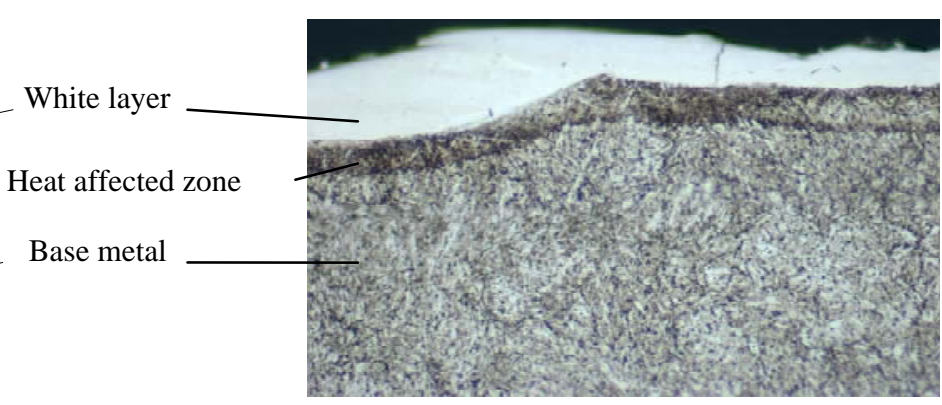

(b)

Fig. 2 Different layers formed on the EDM machined surface. (a) Ti electrode and (b) Cu electrode.

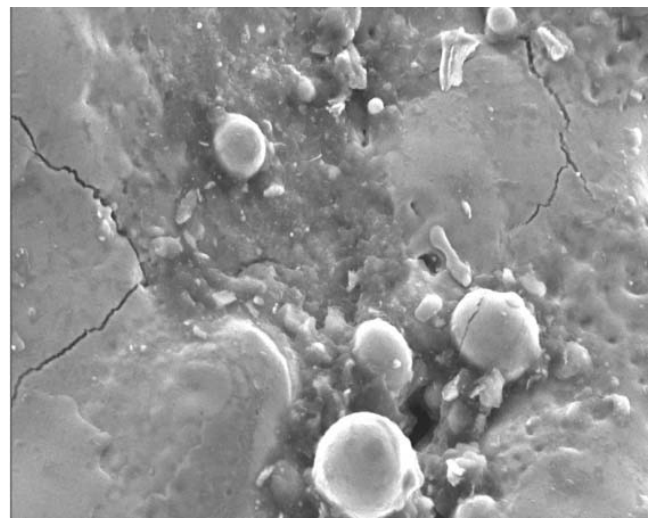

(a)

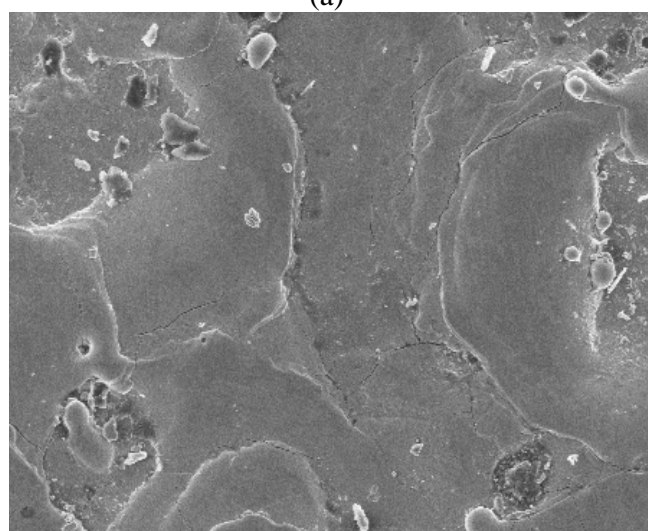

(c)

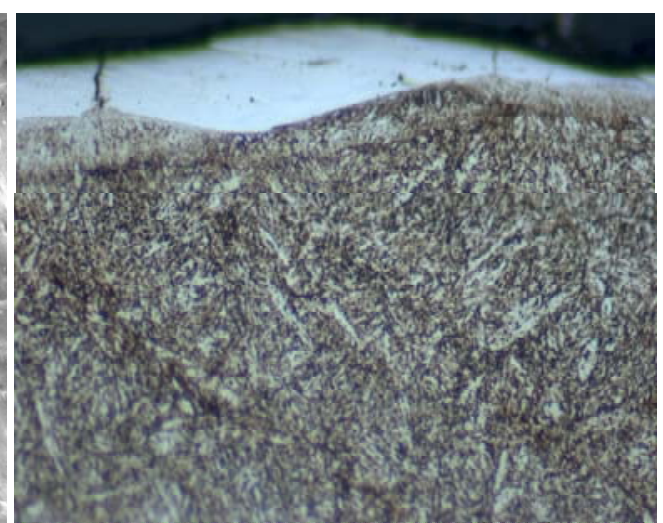

(b)

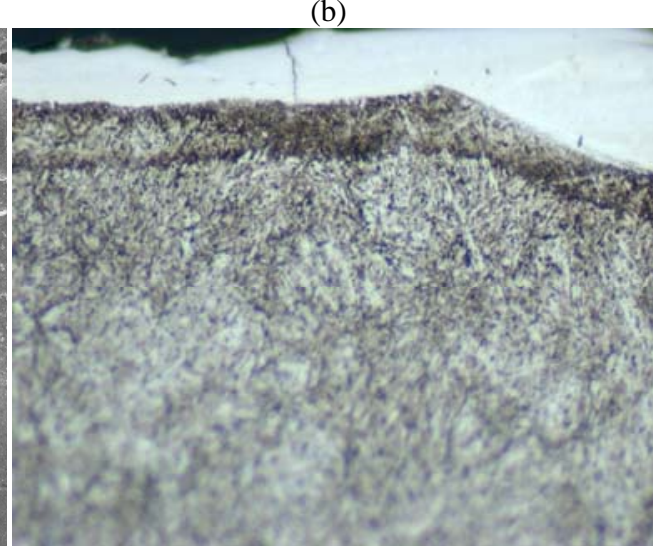

(d)

Fig. 3 Cracks on workpiece surfaces. (a) Tracking of cracks (Ti electrode), (b) depth of cracks (Ti electrode), (c) tracking of cracks (Cu electrode) and (d) depth of cracks (Cu electrode).

Table 2 Depth of altered metal zone layers.

\begin{tabular}{lrr}
\hline \multirow{2}{*}{ Altered metal zone layers } & \multicolumn{2}{c}{ Depth $(\mu \mathrm{m})$} \\
\cline { 2 - 3 } & \multicolumn{1}{c}{ Cu electrode } & \multicolumn{1}{c}{ Ti electrode } \\
\hline White layer & $10.54 \div 24.06$ & $15.13 \div 24.06$ \\
Heat affected zone & $6.21 \div 13.33$ & $8.28 \div 11.51$ \\
\hline
\end{tabular}

Table 3 Micro hardness measurement across transverse sections.

\begin{tabular}{lllllll}
\hline Depth $(\mu \mathrm{m})$ & & 10 & 25 & 100 & 150 & 200 \\
\hline Hardness & Cu electrode & 511.27 & 648.13 & 557.93 & 582.15 & 554.86 \\
$(\mathrm{HV})$ & Ti electrode & 512.133 & 661.01 & 562.11 & 565.9 & 584.38 \\
\hline
\end{tabular}


electrode compared to that produced using a $\mathrm{Cu}$ electrode (Fig. 3).

The microscopic hardness of the white layer in both types of electrode materialsis quite similar $(\mathrm{Cu}$ electrode: $511.27 \mathrm{HV}$, Ti electrode: $512.133 \mathrm{HV}$ ), lower than the hardness of the heat affected zone and base material.

The forging molds, hot dies always work in high temperature environments with high shock pressure. The choosing materials, hardness and surface coating are very important to increase the working accuracy and ability of the molds. From the above results it is observed that the white layer reduces the working capacity of hot die sink.

\subsubsection{The Heat Affected Zone}

This layer is located beneath the white layer and is difficult to be observed clearly. It has lower layer thicker than white layer (Cu electrode: $(6.21 \div 13.33) \mu \mathrm{m}$, Ti electrode: $(8.28 \div 11.51) \mu \mathrm{m}$. This layer is formed when the thermal energy of the sparks makes the material phase changed.

There are few microscopic racks with little depth on the heat affected zone and they do not exist in parallel with the machined surface.

The microscopic hardness of the heat affected zone is very high (Cu electrode: $648.13 \mathrm{HV}$, Ti electrode: $661.01 \mathrm{HV}$ ), higher than the white layer and base metal $(490 \div 547)$ HV.

This layer makes a positive impact on the ability of the hot forging die.

\subsection{Chemical Composition and X-Ray Diffraction} Pattern of Surface Machined

Chemical composition of the machined surface layer was Energy Dispersive Spectroscopy (EDS) analysis. The test results of the chemical compositions and X-ray diffraction pattern of the surface layer are shown in Table 4 and Figs. 4 and 5.

Chemical compositions of the heat affected zone and the base metal are unchanged in die sinking EDM using a tool electrode of $\mathrm{Ti}$ and $\mathrm{Cu}$.

The EDS analysis by ZAF Method Standardless Quantitative Analysis of the white layer chemical compositions are significantly changed.

The EDS analysis of the white layer chemical compositions shows the presence of major constituent elements such as iron, carbon, manganese, silicon, vanadium, chromium, molybdenum and also copper (Cu eletrode) and titanium (Ti electrode) as shown in Fig. 4. The chemical composition of Copper and Titanium is given in Table 4.

The carbon content on the white layer greatly increases (Cu electrode: 14.35\%; Ti electrode: $13.76 \%$ ) because during the pulse the thermal energy of the emitted sparks generated carbon cracking oil, creatingthe carbon entering the machined surface.

Appear selectrode material on the machined surface $(\mathrm{Cu} \approx 0.28 \%, \mathrm{Ti} \approx 1.15 \%)$. This is due to the melting and evaporation of electrode material moving and sticking to the surface of the workpiece.

Table 4 Chemical composition of SKD61 machined.

\begin{tabular}{llcc}
\hline \multirow{2}{*}{$\begin{array}{l}\text { Composition } \\
\text { (\%) }\end{array}$} & \multicolumn{2}{c}{ After machining (\%) } \\
\cline { 2 - 4 } Carbon & 0.40 & Cu electrode & Ti electrode \\
Manganese & 0.47 & 0.39 & 13.76 \\
Silicon & 0.98 & 1.02 & 0.4 \\
Vanadium & 0.83 & 0.66 & 1.00 \\
Chromium & 4.89 & 4.76 & 0.80 \\
Molybdenum & 1.15 & 1.30 & 5.15 \\
Titanium & 0.00 & 0.00 & 1.40 \\
Copper & 0.00 & 0.28 & 1.15 \\
\hline
\end{tabular}



Discharge Machining

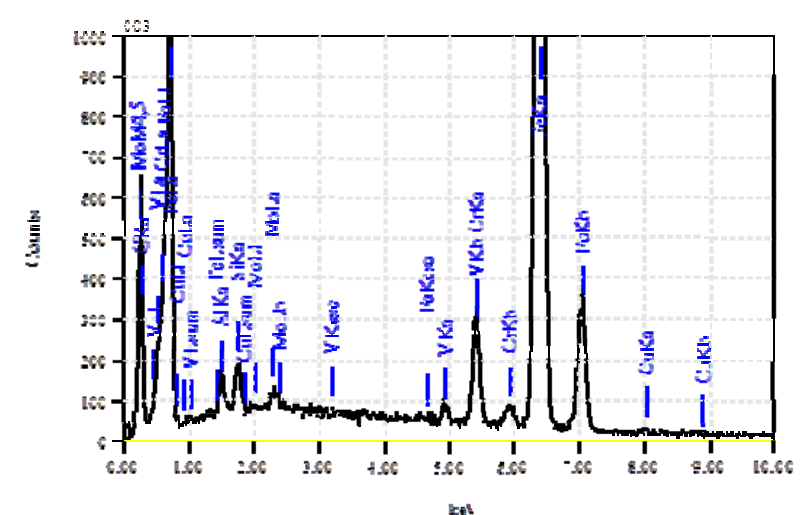

(a)

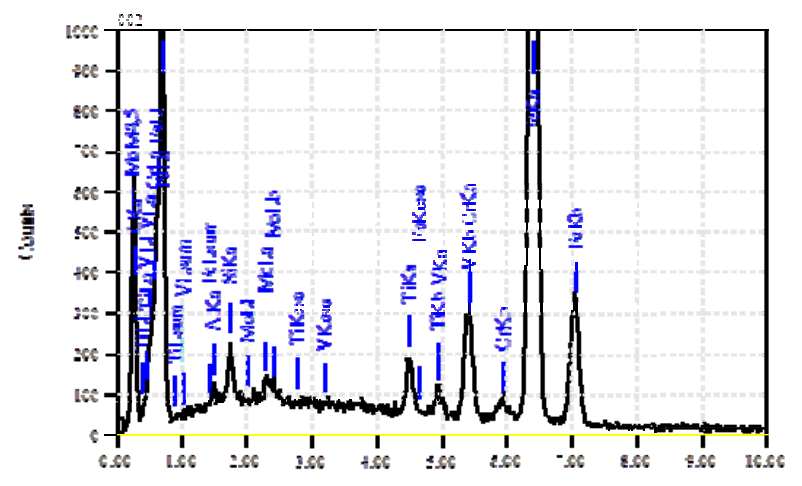

(b)

Fig. 4 EDS analysis of SKD61 machined. (a) Cu electrode and (b) Ti electrode.

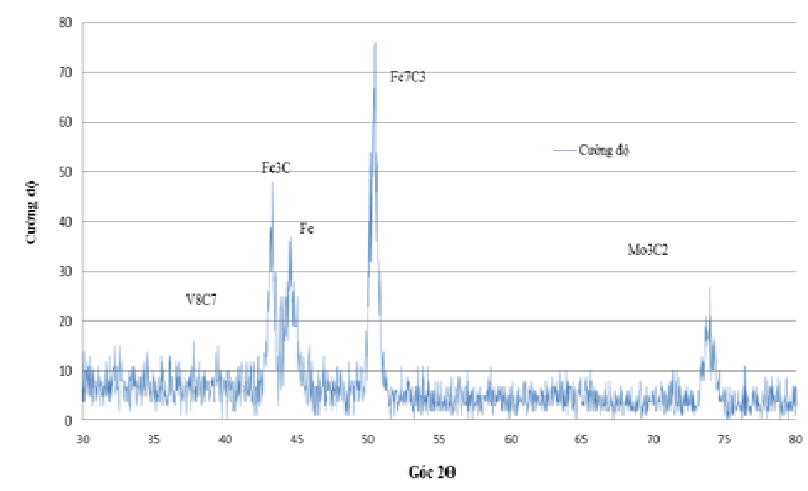

(a)

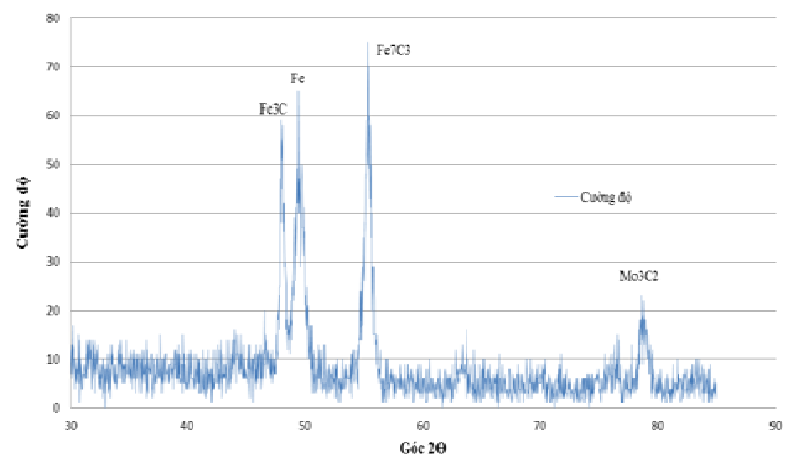

(b)

Fig. 5 X-ray diffraction pattern of SKD61 machined. (a) Cu electrode and (b) Ti electrode.

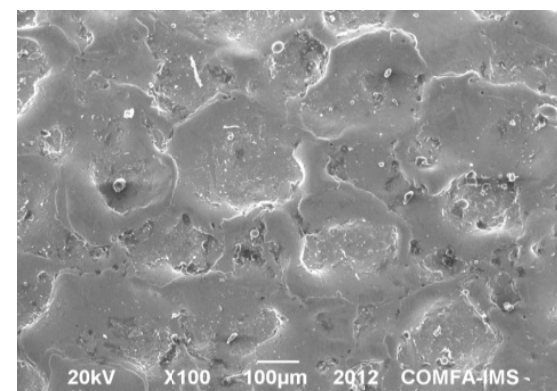

(a)

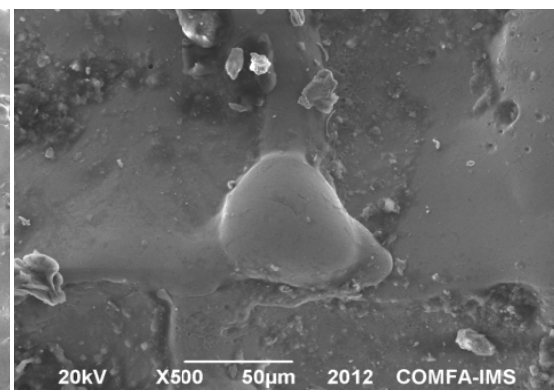

(b)

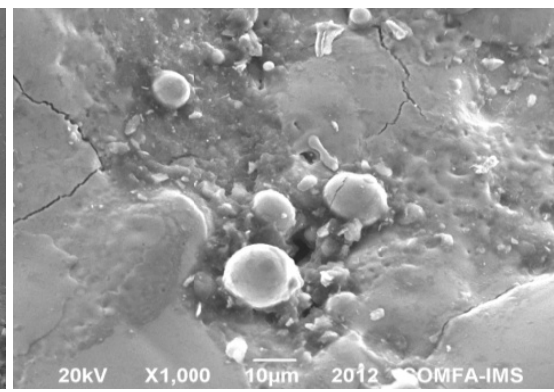

(c)

Fig. 6 Microstructures of SKD61 surface machined (tool electrode of Ti and Cu). (a) EDMed surface, (b) the superimposed craters on the surface and (c) the form of debris particles of EDM.

Carbon decomposed from the working fluid are transferred to the surface layer. Carbon and Iron wetting the surface create carbide $\left(\mathrm{Fe}_{7} \mathrm{C}_{3}\right)$ and martensite $\left(\mathrm{Fe}_{3} \mathrm{C}\right)$.

\subsection{Topography of Surface Machined}

Fig. 6 is SEM images depicting of the surface machined.

The surface gathers many large craters and the sparks generated by the pulse cycle (Fig. 6a) create them.
The craters are on the radius of curvature (the arrows in Fig. 6b) created when the sparks make the materials melting and evaporating affected by the dielectric fluid simultaneously quenching and causing the outer surface tension.

Many small globules of debris appear on the surface, adhesive to processed surface, causing increases surface roughness (Fig. 6c). These global appendages are molten metals which were expelled randomly during the discharge and later solidified on the 
workpiece surfaces. The globules of debris are formed as a result of the molten metal must have solidified at an extremely high rate. Otherwise, the surface tension of the molten metal would have caused the sharp edges to be rounded off.

These cracks are formed as a result of the exceedingly high thermal stresses prevailing at the specimen surface as the latter was cooled at a fast rate after the discharge.

The average surface roughness $\left(\mathrm{R}_{\mathrm{z}}\right)$ of hot forging die surface layer in die sinking EDM process was $(27.0 \div 30.13) \mu \mathrm{m}$. The results show that it needs to have to polish before using.

\section{Conclusions}

The microscopic structure and mechanical properties of the surface machined white layer have negative impact on the ability of the mold. In contrast, the heat affected zone has a higher hardness than the base metal so that it will improve the ability of the mold. There must have research studied on the effect of various parameters to reduce or completely remove a layer white at the surface of a workpiece.

Carbon is cracked from the dielectric, copper and titanium transfer takes place from the tool electrode to the machined surface. However, Titanium carbide (TiC) has not been formed by this method of machining. Although only the elements appear in the white layer but these results suggest are search direction to create surface layer differences inchemical composition and better mechanical quality compared to the base metal, especially, the forma very high hardness (TiC).

Thermal energy of sparks has been generated carbon cracking oil from entering surface machining. Therefore, if we mixed powder metal or powder alloying into a suitable fluid dielectric to achieve similar results. Moreover, also the direction in which to study.

Results show that: The machined surface layers in die sinking EDM using a tool electrode of $\mathrm{Ti}$ and $\mathrm{Cu}$ are quite similar. However, the number of microcracks of $\mathrm{Cu}$ electrode is less than $\mathrm{Ti}$ electrode and the titanium material cost is much higher than copper, so the $\mathrm{Cu}$ electrode would be more appropriate than titanium electrode.

\section{Acknowledgments}

The researcher was presented at Thai Nguyen university of Technology. To obtain the results of this study, the authors would like to thank to diesel limited company, Institute of Materials Science-Vietnam Academy of Science and Technology who helped during the research process.

\section{References}

[1] A.G. Jaharah, C.G. Liang, S.Z. Wahid, M.N.A. Rahman, C.H.C. Hassan, Performance of copper electrode in electical discharge machining (EDM) of AISI H13 harden steel, International Journal of Mechanical and Materials Engineering 3 (1) (2008) 25-29.

[2] K.H. Ho, S.T. Newman, State of the art electrical discharge machining (EDM), International Journal of Machine Tools \& Manufacture 43 (13) (2003) 1287-1300.

[3] H.T. Lee, F.C. Hsu, T.Y. Tai, Study of surface integrity using the small area EDM process with a copper tungsten electrode, Mater. Sci. Eng. A 364 (2004) 346-356.

[4] B. Ekmekci, Residual stresses and white layer in electric discharge machining (EDM), Applied Surface Science 253 (23) (2007) 9234-9240.

[5] M.R. Shabgard, M. Seyedzavvar, S. Oliaei, Influence of input parameters on characteristics of EDM process, Journal of Mechanical Engineering 57 (9) (2011) 689-696.

[6] A. Gangadhar, M.S. Shunmugam, P.K. Philip, Surface modification in electrodischarge processing with a powder compact tool electrode, Wear 143 (1) (1991) 45-55.

[7] N. Mohri, N. Saito, Y. Tsunekawa, Metal surface modification by electrical discharge machining with composite electrode, Annals of the CIRP 42 (1) (1993) 161-194.

[8] S. Kumar, R. Singh, T.P. Singh, B.L. Sethi, Surface modification by electrical discharge machining: A review, Journal of Materials Processing Technology 209 (8) (2009) 3675-3687.

[9] K. Furutani, A. Saneto, H. Takezawa, N. Mohri, H. Miyake, Accretion of tita-nium carbide by electrical discharge machining with powder suspended in working fluid, Precision Engineering 25 (2) (2001)138-144.

[10] B.H. Yan, H.C. Tsai, F.Y. Huang, The effect in EDM of a dielectric of a urea solution in water on modifying the surface of titanium, International Journal of Machine Tools \& Manufacture 45 (2) (2005) 194-200. 